\title{
An artificial lung reduces pulmonary impedance and improves right ventricular efficiency in pulmonary hypertension
}

\author{
Jonathan W. Haft, MD \\ Patrick Montoya, PhD \\ Osamma Alnajjar, MD \\ Steven R. Posner, MD \\ Joseph L. Bull, PhD \\ Mark D. Iannettoni, MD \\ Robert H. Bartlett, MD \\ Ronald B. Hirschl, MD
}

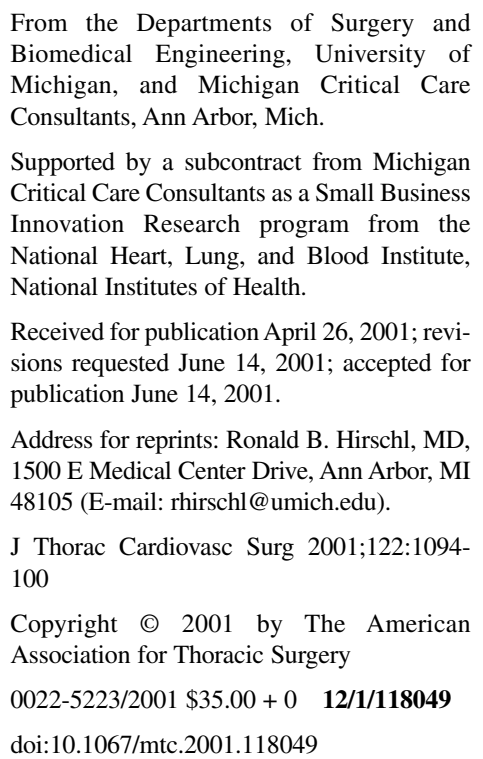

Received for publication April 26, 2001; revisions requested June 14, 2001; accepted for publication June 14, 2001.

Address for reprints: Ronald B. Hirschl, MD, 1500 E Medical Center Drive, Ann Arbor, MI 48105 (E-mail: rhirschl@umich.edu).

J Thorac Cardiovasc Surg 2001;122:1094100

Copyright (C) 2001 by The American Association for Thoracic Surgery

$0022-5223 / 2001 \$ 35.00+0 \quad \mathbf{1 2 / 1 / 1 1 8 0 4 9}$

doi:10.1067/mtc.2001.118049

Objective: Artificial lungs may have a role in supporting patients with end-stage lung disease as a bridge or alternative to lung transplantation. This investigation was performed to determine the effect of an artificial lung, perfused by the right ventricle in parallel with the pulmonary circulation, on indices of right ventricular load in a model of pulmonary hypertension.

Methods: Seven adult male sheep were connected to a low-resistance membrane oxygenator through conduits anastomosed end to side to the pulmonary artery and left atrium. Banding of the distal pulmonary artery generated acute pulmonary hypertension. Data were obtained with and without flow through the device conduits. Outcome measures of right ventricular load included hemodynamic parameters, as well as analysis of impedance, power consumption, wave reflections, cardiac efficiency, and the tension-time index.

Results: The model of pulmonary hypertension increased all indices of right ventricular load and decreased ventricular efficiency. Allowing flow through the artificial lung significantly reduced mean pulmonary artery pressure, zero harmonic impedance, right ventricular power consumption, amplitude of reflected waves, and the tension-time index. Cardiac efficiency was significantly increased.

Conclusions: An artificial lung perfused by the right ventricle and applied in parallel with the pulmonary circulation reduces ventricular load and improves cardiac efficiency in the setting of pulmonary hypertension. These data suggest that an artificial lung in this configuration may benefit patients with end-stage lung disease and pulmonary hypertension with right ventricular strain.

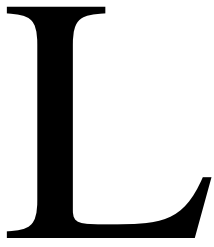

ung transplantation is the only treatment for most patients with endstage lung disease. However, although the candidate registry continues to grow, the number of transplants performed has reached a plateau, limited by the finite pool of cadaveric organs. ${ }^{1}$ Because allocation for lungs in the United States is based entirely on waiting time rather than urgency, the wait-list mortality is exceedingly high. Furthermore, there is reluctance by many centers to perform transplants in patients requiring mechanical ventilation. ${ }^{2}$ For those patients who decompensate while awaiting the availability of a suitable organ, there are currently no options, illustrating the need for new and innovative solutions. 


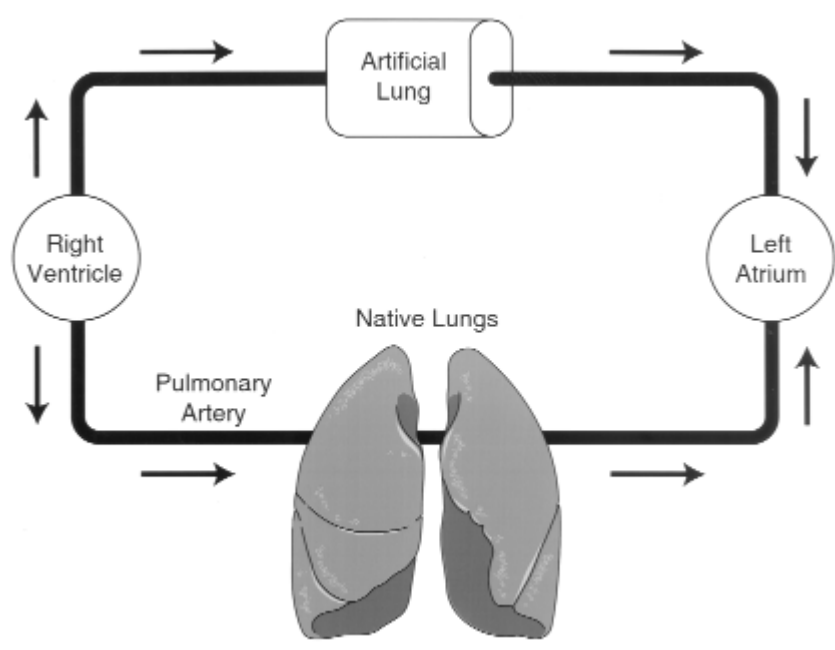

Figure 1. Parallel application of the artificial lung involves sharing right ventricular blood flow with the native lungs. The quantity of diverted blood flow is related to the comparative resistances of the artificial and native lungs.

A pulmonary assist device, or artificial lung, may have a role in supporting these patients as a bridge or even as an alternative to transplantation. Such strategies are now routine with cardiac failure ${ }^{3}$ and have been explored for liver failure. ${ }^{4}$ Although extracorporeal membrane oxygenation has been successfully used as a short-term support for acute respiratory failure, ${ }^{5}$ the inherent complexity and cost are impractical for use beyond several weeks. Design goals for an artificial lung should take into account durability for prolonged support and simplicity, permitting use on an ambulatory basis.

A low-resistance oxygenator can be perfused entirely by the native cardiac output, obviating the need for a mechanical pump. This straightforward design is perhaps the most viable strategy because long-term mechanical pumps may be associated with cellular blood element trauma, may require frequent close monitoring for evidence of failure, and would necessarily increase cost. ${ }^{6}$ Previous studies have demonstrated the feasibility of a pumpless artificial lung applied in a variety of configurations. ${ }^{7-11}$ A lumped parameter model defined the theoretical effect on cardiac load for various applications of an artificial lung perfused by the right ventricle. ${ }^{12}$ This simulated computer model predicted that a device situated in parallel with the pulmonary circulation (Figure 1) would reduce right ventricular power consumption in the setting of elevated pulmonary vascular resistance. Because many patients on the lung transplant waiting list have pulmonary hypertension, particularly those with the highest wait-list mortality, ${ }^{13,14}$ this application may be the most beneficial. We sought to determine, in an in vivo model of pulmonary hypertension, the effect of an artificial lung applied in parallel on indices of right ven-

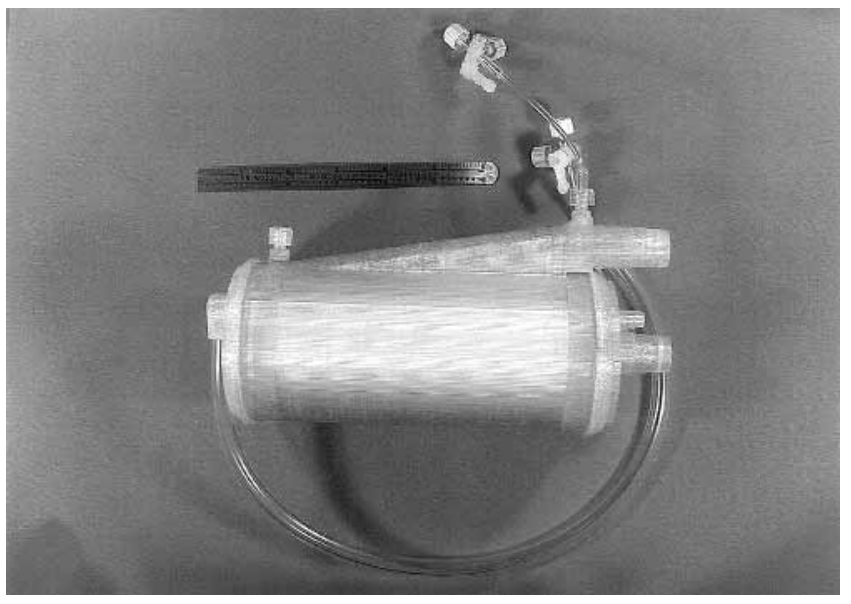

Figure 2. The total artificial lung is a low-resistance oxygenator. Pressure drop in vitro with water is approximately $2.5 \mathrm{~mm} \mathrm{Hg}$, with $5 \mathrm{~L} / \mathrm{min}$ flow.

tricular load. Specifically, we were interested in quantifying and characterizing how this low-resistance but noncompliant oxygenating shunt would influence factors related to pulsatile flow, such as impedance and reflection waves.

\section{Materials and Methods}

\section{Anesthesia and Animal Handling}

Seven adult male sheep $(59 \pm 5 \mathrm{~kg})$ underwent anesthetic induction with sodium thiopental $(7 \mathrm{mg} / \mathrm{kg}$ ) administered intravenously and $0.6 \mathrm{mg}$ of buprenorphine hydrochloride administered intramuscularly. The animals were intubated with an $11 \mathrm{~F}$ cuffed endotracheal tube and ventilated with a Narkomed 2 anesthesia machine (North American Drager, Telford, Pa), maintaining continuous inhalational anesthesia with isoflurane $0.4 \%$ to $4.0 \%$. Respiratory rate and tidal volumes were adjusted to maintain a $\mathrm{PaCO}_{2}$ of between 35 and $45 \mathrm{~mm} \mathrm{Hg}$ and a peak inspiratory pressure of less than $30 \mathrm{~cm} \mathrm{H}_{2} \mathrm{O}$. Positive end-expiratory pressure of 5 $\mathrm{cm} \mathrm{H}_{2} \mathrm{O}$ was applied continuously. Animals received humane care in compliance with the National Society for Medical Research, as well as the Institute of Laboratory Animal Resources. The University of Michigan Committee on the Use and Care of Animals (protocol No. 7239) approved all experiments.

\section{Instrumentation}

With the animal supine, the right femoral artery was exposed. An arterial catheter was inserted and connected to a fluid-coupled strain-gauge pressure transducer (Abbott Critical Care Systems, Chicago, Ill), and the resulting arterial pressure signal was displayed continuously (Marquette Electronics, Milwaukee, Wis).

A muscle-sparing left anterolateral thoracotomy in the fourth intercostal space was performed, resecting a portion of the fifth rib for exposure. The pericardium was incised, and the pulmonary artery (PA) was isolated from the pulmonic valve to the bifurcation. A side-mounted pressure-sensing micromanometer (Millar 
TABLE 1. Indices of cardiac load and function during baseline conditions and in the setting of acute pulmonary hypertension, with and without flow through the artificial lung

\begin{tabular}{|c|c|c|c|c|c|}
\hline & Baseline & $\begin{array}{l}\text { PH: artificial } \\
\text { lung clamped }\end{array}$ & $\begin{array}{l}\text { PH: artificial } \\
\text { lung open }\end{array}$ & $\begin{array}{c}\text { Pvalue, } \\
\text { PH: artificial } \\
\text { lung clamped vs } \\
\text { PH: artificial } \\
\text { lung open }\end{array}$ & Change (\%) \\
\hline $\mathrm{mP}_{\mathrm{Ao}}(\mathrm{mm} \mathrm{Hg})$ & $91.7 \pm 4.2$ & $53.9 \pm 3.1^{*}$ & $73.4 \pm 5.4$ & .008 & +36 \\
\hline $\mathrm{CO}(\mathrm{L} / \mathrm{min})$ & $5.8 \pm 0.9$ & $4.7 \pm 0.4$ & $4.7 \pm 0.5$ & .9 & +0 \\
\hline $\mathrm{mP}_{\mathrm{pa}}(\mathrm{mm} \mathrm{Hg})$ & $14.8 \pm 1.0$ & $28.5 \pm 0.7^{*}$ & $15.5 \pm 0.7$ & $<.001$ & -46 \\
\hline $\mathrm{Z}_{0}$ (Wood units) & $2.8 \pm 0.3$ & $6.3 \pm 0.5^{*}$ & $3.5 \pm 0.6$ & $<.001$ & -44 \\
\hline $\mathrm{Z}_{1}$ (Wood units) & $0.39 \pm 0.03$ & $2.95 \pm 0.25^{*}$ & $2.3 \pm 0.24$ & .14 & -22 \\
\hline $\mathrm{Z}_{\mathrm{c}}$ (Wood units) & $0.56 \pm 0.05$ & $1.93 \pm 0.18^{*}$ & $1.4 \pm 0.19$ & .09 & -27 \\
\hline$P_{b}(m m ~ H g)$ & $0.50 \pm 0.12$ & $1.35 \pm 0.15$ & $0.93 \pm 0.11$ & .02 & -31 \\
\hline$W_{t}(m W)$ & $234.9 \pm 39.2$ & $380.7 \pm 39.5^{*}$ & $231.5 \pm 37.8$ & $<.001$ & -39 \\
\hline $\mathrm{CO}_{\mathrm{t}}(\mathrm{L} / \mathrm{J})$ & $25.4 \pm 1.3$ & $12.6 \pm 0.4^{*}$ & $21.0 \pm 1.2$ & $<.001$ & +67 \\
\hline$W_{m}(m W)$ & $193.1 \pm 32.1$ & $298.7 \pm 25.8^{*}$ & $158.9 \pm 23.4$ & $<.001$ & -47 \\
\hline$W_{o s c}(m W)$ & $41.8 \pm 8.0$ & $82.0 \pm 17.8^{*}$ & $72.6 \pm 18.4$ & .35 & -11 \\
\hline TTI (mm Hg - s/min) & $483.5 \pm 42.7$ & $1184.6 \pm 52.6^{*}$ & $708.2 \pm 42.0$ & $<.001$ & -40 \\
\hline
\end{tabular}

Values are expressed as means $\pm \mathrm{SE}$. $P H$, Pulmonary hypertension; $m P_{A 0^{\prime}}$ mean systemic arterial pressure; $m P_{P A^{\prime}}$ mean pulmonary arterial pressure; $Z_{0}$, zero harmonic; $P_{b}$, amplitude of the reflected pressure wave; $W_{t}$, total hydraulic power; $C O / W_{t}$, ventricular efficiency; $W m$, steady hydraulic power; $W_{\text {osc }}$ oscillatory hydraulic power; TTI, tension-time index.

*Denotes $P<.05$ versus baseline conditions.

Instruments, Inc, Houston, Tex) was inserted into the proximal PA immediately distal to the valve, and the PA pressure $\left(\mathrm{P}_{\mathrm{PA}}\right)$ signal was displayed continuously. An ultrasonic flow probe (Transonic 24A159; Transonic Systems, Inc, Ithaca, NY) was placed around the proximal PA to measure instantaneous PA flow $\left(\mathrm{Q}_{\mathrm{PA}}\right)$ and mean PA flow (cardiac output [CO]) with a flowmeter (Transonic T106). The micromanometer and flow probe were situated such that $\mathrm{P}_{\mathrm{PA}}$ and $\mathrm{Q}_{\mathrm{PA}}$ were sampled from the same location. A catheter was placed in the left superior pulmonary vein and connected to a fluid-coupled strain-gauge pressure transducer for continuous left atrial pressure measurement.

\section{Artificial Lung and Acute Pulmonary Hypertension}

Inflow and outflow conduits for the artificial lung consisted of 16mm Hemashield vascular grafts (Boston Scientific, Natick, Mass) solvent bonded to $5 / 8$-inch polyvinyl chloride tubing. The grafts were preclotted, and the animal was anticoagulated with 100 IU/kg intravenous sodium heparin. The inflow conduit was anastomosed end to side to the PA, distal to the flow probe and micromanometer. The outflow conduit was anastomosed to the left atrial appendage. The artificial lung (Michigan Critical Care Consultants, Ann Arbor, Mich) is a radial flow oxygenator containing microporous hollow fibers with a surface area of $2.25 \mathrm{~m}^{2}$ as the gas-exchange substrate (Figure 2). The polypropylene fibers (Celgard Inc, Charlotte, NC) have an external diameter of $300 \mu \mathrm{m}$, a pore size of $0.03 \mu \mathrm{m}$, and a porosity of $40 \%$. Bench-top testing of the artificial lung demonstrates a rated flow of $9.0 \mathrm{~L} / \mathrm{min}$ and steady flow resistance of 0.5 Wood units in water. The device was primed with approximately $280 \mathrm{~mL}$ heparinized saline solution and connected to the conduits. Once de-airing was complete, the conduit clamps were removed to establish flow. An ultrasonic flow probe (Transonic H13X6) was placed around the inflow conduit tubing and connected to a flowmeter (Transonic HT110). Oxygen sweep gas flow was adjusted to maintain a $\mathrm{PaCO}_{2}$ of between 35 and $45 \mathrm{~mm} \mathrm{Hg}$. Anastomotic patency and hemostasis were confirmed, and the conduits were reclamped to restore the native pulmonary circulation. A flow occluder was then placed around the distal PA near the bifurcation for generation of acute pulmonary hypertension. The occluder was gradually inflated until mean $\mathrm{P}_{\mathrm{PA}}$ was approximately twice baseline values, not allowing $\mathrm{CO}$ to fall below $3.5 \mathrm{~L} / \mathrm{min}$.

\section{Data Acquisition}

Data were collected at a sampling frequency of $300 \mathrm{~Hz}$ through a 6-channel circuit board and Labview software (National Instruments, Austin, Tex) and stored on a personal computer (Apple Computers, Cupertino, Calif). Three conditions were evaluated for each animal: (1) baseline (before device application); (2) in the setting of acute pulmonary hypertension, with the artificial lung conduits clamped; and (3) in the setting of acute pulmonary hypertension, with flow through the artificial lung. Data were collected for 30 continuous seconds after equilibration had been reached, which was determined by stable $\mathrm{P}_{\mathrm{PA}}$, arterial pressure signal, $\mathrm{CO}, \mathrm{PaCO}_{2}$, and oxygen saturation values. Data were then analyzed on a personal computer (Dell Computer, Austin, Tex).

\section{Outcomes Analysis}

Impedance is the resistance to pulsatile flow and best characterizes cardiac load. ${ }^{15}$ Fourier analysis was performed on $\mathrm{P}_{\mathrm{PA}}$ and $\mathrm{Q}_{\mathrm{PA}}$, 


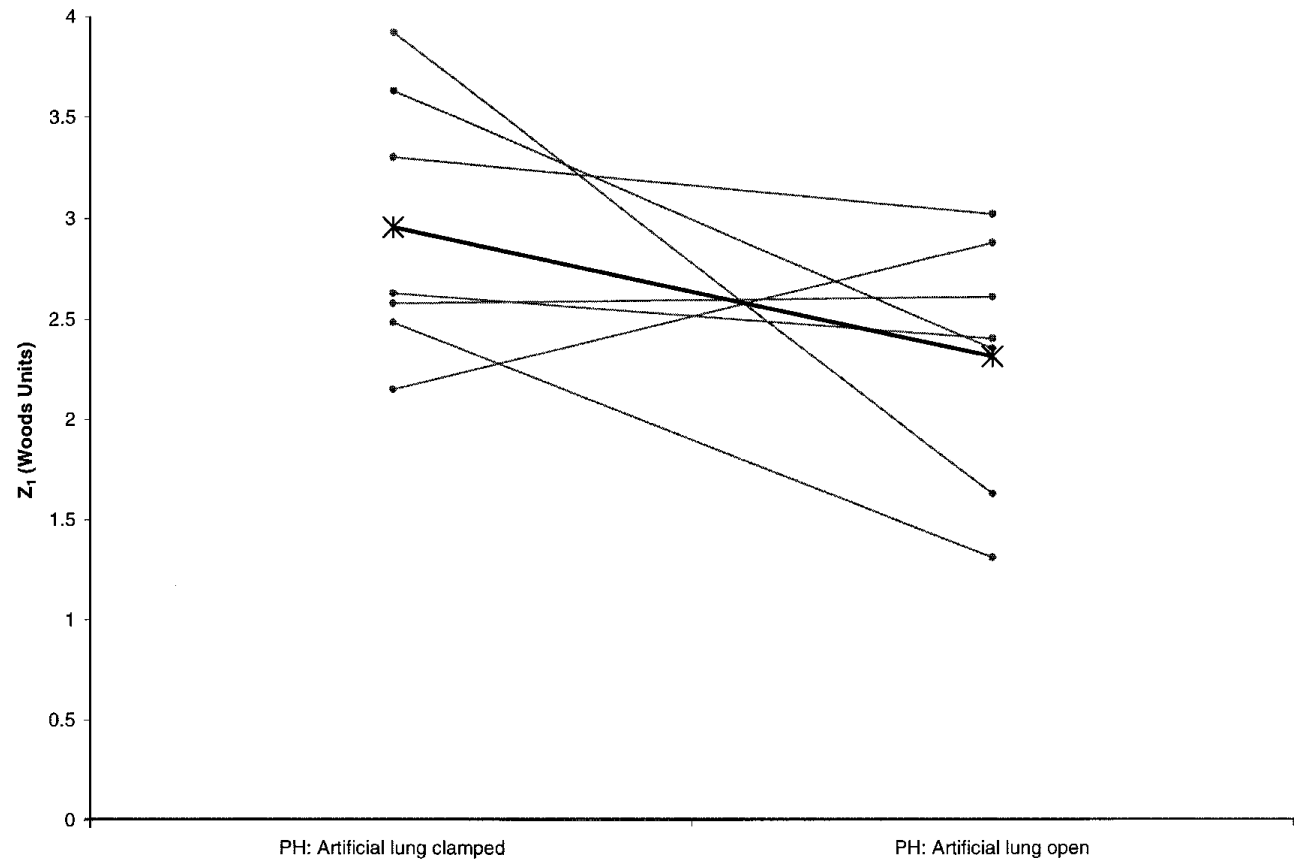

Figure 3. Low-frequency impedance $\left(Z_{1}\right)$ in the setting of acute pulmonary hypertension $(P H)$ with and without flow through the artificial lung. The thick black line represents the mean value.

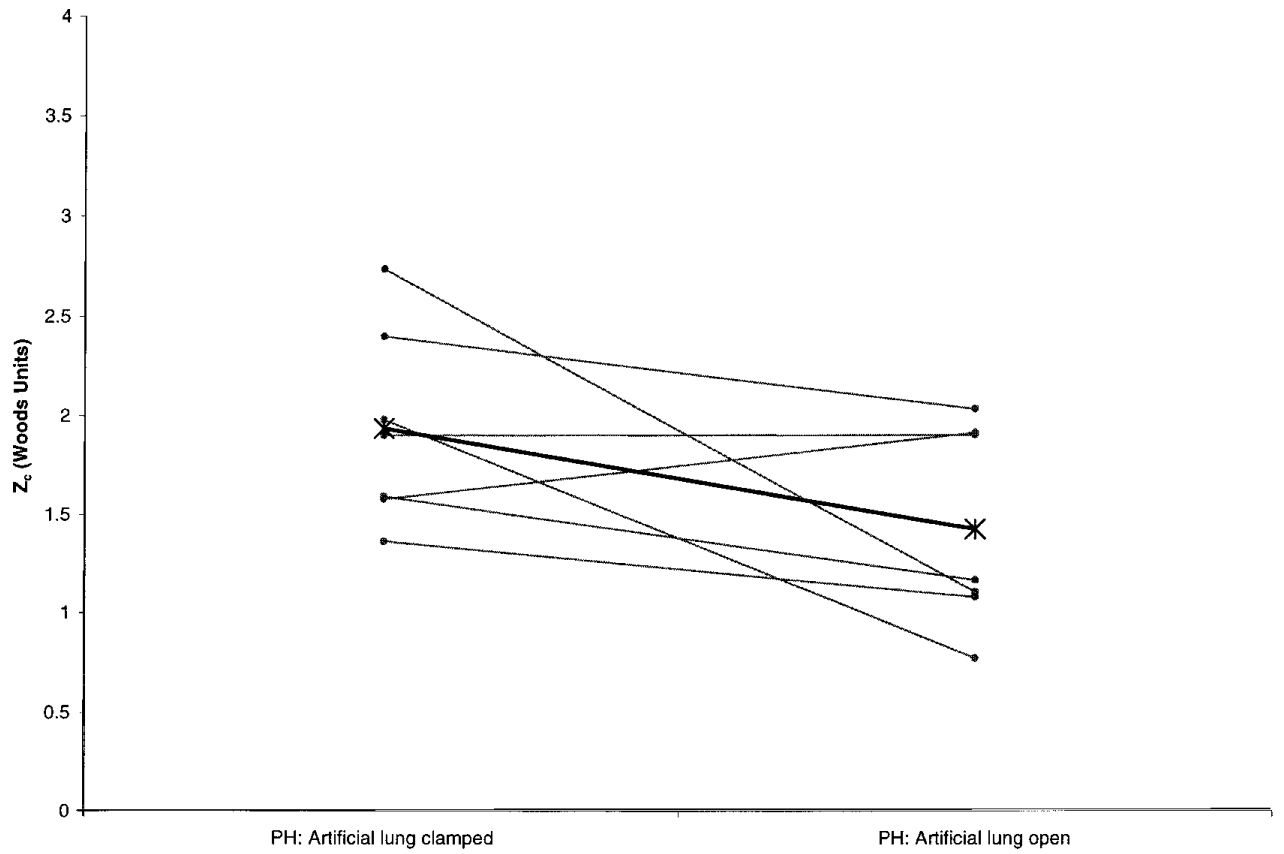

Figure 4. Characteristic impedance $\left(Z_{c}\right)$ in the setting of acute pulmonary hypertension $(P H)$ with and without flow through the artificial lung. The thick black line represents the mean value.

breaking down the waveforms into their respective harmonics with available software (MathWorks, Natick, Mass). Impedance was calculated by dividing the amplitudes of $\mathrm{P}_{\mathrm{PA}}$ and $\mathrm{Q}_{\mathrm{PA}}$ at each harmonic. Resistance is defined by the impedance at the zero harmonic, and low-frequency impedance is defined by the impedance at the first harmonic $\left(\mathrm{Z}_{1}\right)$. Characteristic impedance $\left(\mathrm{Z}_{\mathrm{c}}\right)$, or impedance in the absence of wave reflections, can be estimated by the average impedance between 2 and $12 \mathrm{~Hz} .{ }^{16}$ Signal noise generation was determined by measuring the oscillations in vitro during steady state. Harmonics in which pressure and flow amplitudes 


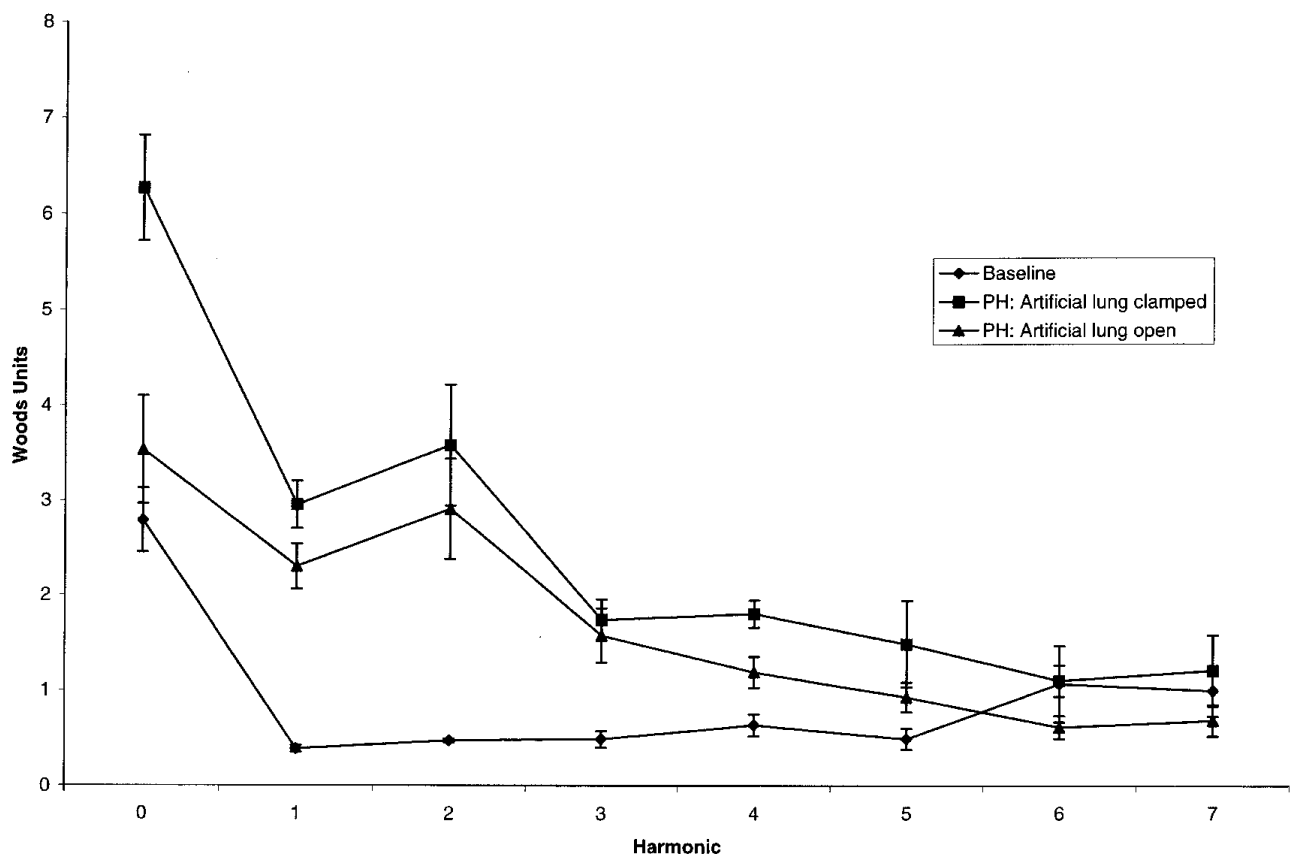

Figure 5. Mean values of pulmonary input impedance spectra at baseline and in the setting of acute pulmonary hypertension (PH) with and without flow through the artificial lung. Error bars reflect SE.

exceeded the in vitro-determined noise magnitudes were excluded from calculations.

When there is a change in the physical properties of a conduit carrying pulsatile flow, pressure waves are reflected backward, increasing cardiac load. A measured pressure wave is therefore the sum of its forward and backward components. The backward component can be determined with the following formula:

$$
\mathrm{P}_{\mathrm{b}}=\left(\mathrm{P}_{\mathrm{PA}}-\mathrm{Z}_{\mathrm{c}} \mathrm{Q}_{\mathrm{PA}}\right) / 2
$$

where $\mathrm{P}_{\mathrm{b}}$ is the backward pressure wave. ${ }^{17}$ The amplitude of $\mathrm{P}_{\mathrm{b}}$ oscillations was determined by Fourier analysis.

Total right-side heart power $\left(\mathrm{W}_{\mathrm{t}}\right)$, or energy consumed, was determined by the time-averaged integral of the product of $\mathrm{P}_{\mathrm{PA}}$ and $\mathrm{Q}_{\mathrm{PA}}$. Mean power $\left(\mathrm{W}_{\mathrm{m}}\right)$ is the energy expended to produce forward flow and is the product of mean $\mathrm{P}_{\mathrm{PA}}$ and $\mathrm{CO}$. Oscillatory power represents energy wasted in oscillations without generating flow and can be determined by $\mathrm{W}_{\mathrm{t}}-\mathrm{W}_{\mathrm{m}} \cdot{ }^{15} \mathrm{CO} / \mathrm{W}_{\mathrm{t}}$, or flow generated per unit of energy consumed, is an index of ventricular efficiency. ${ }^{16}$ The tension-time index is a correlate of myocardial oxygen consumption and was determined by the product of the $\mathrm{P}_{\mathrm{PA}}$ integral during systole and the heart rate. ${ }^{18}$

\section{Statistical Analysis}

Data are expressed as means \pm SE. Statistical analyses were performed with a Student 2-tailed paired $t$ test.

\section{Results}

All animals tolerated instrumentation and application of the artificial lung, as described. During the generation of acute pulmonary hypertension, all animals had systemic hypoten- sion, but $\mathrm{CO}$ did not fall to less than $3.5 \mathrm{~L} / \mathrm{min}$. The model of pulmonary hypertension increased all measured indices of right ventricular load, as shown in Table 1, with an approximate $50 \%$ reduction in ventricular efficiency.

Unclamping of the conduits resulted in diverting a portion of the right ventricular output through the artificial lung. The quantity of blood diverted through the device ranged from 2.5 to $4.6 \mathrm{~L} / \mathrm{min}$ or $71 \% \pm 5 \%$ of the total right ventricular output. Oxyhemoglobin saturation of the blood exiting the device was always $100 \%$. Significant reductions in mean $\mathrm{P}_{\mathrm{PA}}$, zero harmonic, tension-time index, $\mathrm{W}_{\mathrm{t}}, \mathrm{W}_{\mathrm{m}}$, and $\mathrm{P}_{\mathrm{b}}$ values were observed, with an increase in ventricular efficiency (Table 1). Although not achieving statistical significance, $Z_{1}$ and $Z_{c}$ trended downward (Figures 3 and 4). Input impedance spectra for all 3 conditions are depicted in Figure 5.

\section{Discussion}

Artificial organs have prolonged survival and improved quality of life for patients with a variety of types of organ failure. Artificial lungs may provide such a benefit to those patients with end-stage lung disease, either as a bridge or as an alternative to lung transplantation. A device designed for this purpose must be capable of satisfying the gas-exchange requirements of these patients for a prolonged period, with minimal stress on other organ systems. Because experience with ventricular assist devices has demonstrated improved outcomes for patients successfully managed on an ambula- 
tory basis, ${ }^{6}$ an artificial lung should be uncomplicated enough to allow similar patient independence. A strategy in which a pumpless oxygenator is used as an artificial lung, as demonstrated in this study, would simplify the design, which may facilitate ambulatory use, minimize blood trauma, and diminish cost.

The native cardiac output can perfuse a low-resistance oxygenator through several theoretical configurations. An arteriovenous approach, in which arterial blood is shunted through the device, takes advantage of the more powerful and tolerant left ventricle; however, it is limited primarily to carbon dioxide removal. ${ }^{10,11}$ In contrast, venous blood, because of its lower oxyhemoglobin saturation, must be used to optimize oxygen transfer. A pulmonary replacement, in which the entire right ventricular output is diverted from the main PA to the artificial lung and returned directly into the left atrium, may induce cardiac failure or dysfunction if the resistance and compliance of the artificial lung differs significantly from that of the native lung. ${ }^{12}$ In addition, total elimination of pulmonary blood flow may exacerbate lung failure by causing ischemia or thrombosis. ${ }^{9}$

As an alternative to pulmonary replacement, an artificial lung can be perfused by the right ventricle either in series or in parallel with the native lungs. An in-series approach would divert the entire cardiac output through the device but return the oxygenated blood back into the distal PA, therefore preserving native pulmonary blood flow. This configuration also allows the lungs to serve as an embolic trap for microthrombi. However, we have previously shown that the added resistance frequently overloads an untrained and fragile right ventricle. ${ }^{8}$

Parallel application involves shunting a portion of the cardiac output through the device, with return of flow directed into the left atrium. The comparative resistance of the artificial and native lungs would determine the quantity of diverted blood flow. There are several drawbacks to the parallel approach. Because venous blood flow is shared between the artificial and native lungs, oxygen delivery by the device is dependent on the quantity of shunted flow. In addition, outflow is directed into the left atrium, permitting thrombus or air emanating from the device to enter the systemic circulation. However, the distinct advantage of the parallel approach is the potential unloading of the right ventricle, particularly in the setting of pulmonary hypertension.

This study quantified and characterized the magnitude of right ventricular unloading by an artificial lung applied in parallel in a model of pulmonary hypertension. As expected, parallel application greatly reduced indices of ventricular load associated with steady or constant flow, such as mean $\mathrm{P}_{\mathrm{PA}}$, resistance, and $\mathrm{W}_{\mathrm{m}}$, often by as much as $50 \%$. If these reductions could be extrapolated to patients with primary pulmonary hypertension, a $50 \%$ reduction in $\mathrm{P}_{\mathrm{PA}}$ is equivalent to the best therapies currently available. ${ }^{19}$
Marked improvements in the tension-time index, ventricular efficiency, and total power consumption further illustrate the significant benefit to the right ventricle.

The artificial lung used in this study, although extremely low in resistance, is without compliance. This rigidity may impede pulsatile flow and generate pressure-wave reflections. However, this study demonstrated reduced amplitudes of pressure-wave reflections and decreased impedance at every harmonic (Figure 5). Low-frequency impedance, measured at the first harmonic, may have particular physiologic importance because the first harmonic contains the majority of the pulsatile flow. ${ }^{20}$ There appeared to be a reduction in low-frequency impedance, although this did not achieve statistical significance (Figure 3).

Characteristic impedance is defined by impedance in the absence of wave reflections and can be used as a measure of vascular compliance or arterial stiffness. ${ }^{15}$ Interestingly, parallel application of the noncompliant artificial lung produced a trend toward reduction in $\mathrm{Z}_{\mathrm{c}}$ (Figure 4). The mechanism of this likely involves changing the properties of the proximal pulmonary tree. As vessels become increasingly distended, their compliance decreases. Decompression through the artificial lung decreases $\mathrm{P}_{\mathrm{PA}}$ and therefore reduces PA distension. Perhaps reevaluation of this application of the artificial lung in a model of pulmonary hypertension that produces an even greater increase in $\mathrm{P}_{\mathrm{PA}}$ may enhance changes in $\mathrm{Z}_{\mathrm{c}}$.

The gas-exchange efficiency of the artificial lung used in this study has been previously described. ${ }^{7}$ Oxygen transfer is limited only by blood-flow rate and hemoglobin concentration. Because blood flow is shared between the artificial and native circulations, the device will not satisfy the entire oxygenation requirements. However, this study demonstrated, in a model with modest elevation in pulmonary vascular resistance, that the majority of venous blood is shunted through the artificial lung. Assuming a hemoglobin concentration of $14 \mathrm{mg} / \mathrm{dL}$ and a mixed venous oxyhemoglobin saturation of $75 \%$, this translates into an oxygen delivery between 120 and $220 \mathrm{~mL} / \mathrm{min}$.

The model of pulmonary hypertension used in this study does not accurately reflect the hydraulic load seen in patients with pulmonary hypertension. Others have shown that PA banding produces an impedance spectra very dissimilar to that seen in microembolic or primary pulmonary hypertension. ${ }^{21,22}$ The significant elevation in $\mathrm{Z}_{1}$ and $\mathrm{P}_{\mathrm{b}}$ seen in our model may explain why all of the animals had systemic hypotension with only mild elevation of $\mathrm{P}_{\mathrm{PA}}$. Comparison with other known animal models of pulmonary hypertension may better characterize the potential effect of a parallel application of the artificial lung in patients with pulmonary hypertension.

In summary, this study evaluated the hemodynamic benefit to right ventricular load of an artificial lung applied in 
parallel with the pulmonary circulation. Marked reductions in $\mathrm{W}_{t}$ requirements and improvements in efficiency were seen in the setting of acute pulmonary hypertension and attributed to reductions in resistance and pressure-wave reflections and possibly increased compliance. In addition, in this model with relatively mild elevation in $\mathrm{P}_{\mathrm{PA}}$, approximately two thirds of venous blood flow is passively shunted through the artificial lung, thereby supplying the majority of the gas exchange necessary in these animals. Further testing in more clinically relevant models of pulmonary hypertension will be enlightening; however, these preliminary data suggest the potential of an artificial lung in unloading the strained right ventricle.

\section{References}

1. Arcasoy SM, Kotloff RM. Medical progress: lung transplantation. $N$ Engl J Med. 1999;340:1081-91.

2. Maurer JR, Frost AE, Estenne M, Higenbottam T, Glanville AR. International guidelines for the selection of lung transplant candidates. Transplantation. 1998;66:951-6.

3. Minami K, El-Banayosy A, Sezai A, et al. Morbidity and outcome after mechanical ventricular support using Thoratec, Novacor, and Heartmate for bridging to heart transplantation. Artif Organs. 2000;24:421-6.

4. Stockmann HB, Hiemstra CA, Marquet RL, IJzermans JN. Extracorporeal perfusion for the treatment of acute liver failure. Ann Surg. 2000;231:460-70.

5. Kolla S, Awad SS, Rich PB, Schreiner RJ, Hirschl RB, Bartlett RH. Extracorporeal life support for 100 adult patients with severe respiratory failure. Ann Surg. 1997;226:544-64.

6. Goldstein DJ, Oz MC, Rose EA. Medical progress: implantable left ventricular assist devices. N Engl J Med. 1998;339:1522-33.

7. Fazzalari FL, Montoya PJ, Bonnell MR, Bliss DW, Hirschl RB, Bartlett RH. The development of an implantable artificial lung. ASAIO J. 1994;40:M728-31.

8. Lynch WR, Montoya PJ, Brandt DO, Schreiner RJ, Iannettoni MD, Bartlett RH. Hemodynamic effect of a low resistance artificial lung in series with the native lungs of sheep. Ann Thorac Surg. 2000;69:351-6.
9. Cook KE, Makarewicz AJ, Backer CL, Mockros LF, Przybylo HJ, Crawford SE, et al. Testing of an intrathoracic artificial lung in a pig model. ASAIO J. 1996;42:M604-9.

10. Zwischenberger JB, Conrad SA, Alpard SK, Grier LR, Bidani A. Percutaneous extracorporeal arteriovenous $\mathrm{CO}_{2}$ removal for severe respiratory failure. Ann Thorac Surg. 1999;68:181-7.

11. De Somer F, Van Belleghem Y, Foubert L, Caes F, Francois K, Dubrulle F, et al. Feasibility of a pumpless extracorporeal respiratory assist device. J Heart Lung Transplant. 1999;18:1014-7.

12. Boschetti F, Perlman CE, Cook KE, Mockros LF. Hemodynamic effects of attachment modes and device design of a thoracic artificial lung. ASAIO J. 2000;46:42-8.

13. Hosenpud JD, Bennett LE, Keck BM, Edwards EB, Novick RJ. Effect of diagnosis on survival benefit of lung transplantation for end-stage lung disease. Lancet. 1998;351:24-7.

14. DeMeester J, Smits JMA, Persijn GG, Haverich A. Lung transplant waiting list: differential outcome of type of end-stage lung disease, one year after registration. J Heart Lung Transplant. 1999;18:563-71.

15. Milnor WR. Pulsatile blood flow. N Engl J Med. 1972;287:27-34.

16. Bittner HB, Chen EP, Kendall SW, Biswas SS, Davis RD, Van Trigt P. Right ventricular function in orthotopic total atrioventricular heart transplantation. J Heart Lung Transplant. 1998;17:826-34.

17. Westerhof N, Sipkema P, Van Den Bos GC, Elzinga G. Forward and backward waves in the arterial system. Cardiovasc Res. 1972;6:648-56.

18. Sarnoff SJ, Braunwald E, Welch GH, Case RB, Stainsby WN, Macruz R. Hemodynamic determinants of oxygen consumption of the heart with special reference to the tension-time index. Am $J$ Physiol. 1958:192:148-56.

19. McLaughlin V, Genthner D, Panella M, Rich S. Reduction in pulmonary vascular resistance with long term epoprostenol (prostacyclin) therapy in primary pulmonary hypertension. $N$ Engl $J$ Med. 1998;338:273-7.

20. Kussmaul WG, Altschuler JA, Matthai WH, Laskey WK. Heart failure: right ventricular-vascular interaction in congestive heart failure: importance of low frequency impedance. Circulation. 1993;88:1010-5.

21. Calvin JE, Baer RW, Glantz SA. Pulmonary artery constriction produces a greater right ventricular dynamic afterload than lung microvascular injury in the open chest dog. Circ Res. 1985;56:40-56.

22. Laskey WK, Ferrari VA, Palevsky HI, Kussmaul WG. Pulmonary artery hemodynamics in primary pulmonary hypertension. $J$ Am Coll Cardiol. 1993;21:406-12. 